\title{
STRATEGI PEMASARAN BISNIS PARIWISATA DI KOTA DAVAO, FILIPINA ${ }^{1}$
}

\author{
Soehardi'; Sherlito C. Sable ${ }^{2}$ \\ Program Studi Fakultas Ekonomi Universitas Bhayangkara Jakarta Raya ${ }^{1}$ \\ College of Business Administration, University of Southeastern Philippines ${ }^{2}$ \\ soehardi@dsn.ubharajaya.ac.id ${ }^{1}$; sherlito.c.sable.@yahoo.com²
}

\begin{abstract}
ABSTRAK
Penelitian ini bertujuan untuk mengetahui external and internal factors strategi pemasaran bisnis pariwisata di Kota Davao, Filipina. Metode penelitian ini adalah qualitative method. Populasi dalam penelitian ini adalah seluruh anggota travel and tour di Davao City, Philippines dengan menggunakan purposive sampling diperoleh sampel 100. Data primer terdiri dari wawancara dengan kuesioner, observasi lapangan dan dokumentasi. Data sekunder diperoleh dari Davao City Tourism Office, Department of Tourism in Region XI, National Economic and Development Authority (NEDA) Region XI, Bureau of Immigration in Region XI, Davao City Travel and Tours. Analisa data dengan menggunakan Strengths, Weaknesses, Opportunities and Threats (SWOT) Analysis, Internal Factors Analysis Summary (IFAS) and External Factor Analysis Summary (EFAS) membuktikan bahwa strategi pemasaran bisnis pariwisata di Davao City, Philippines, berada pada posisi Kuadran Pertama yang terletak antara peluang eksternal dan kekuatan internal di mana hasil analisis diperoleh skor total IFAS adalah 3,36 dan EFAS adalah 3,01 serta berada pada titik X 3,36 dan titik Y 1,57. Hal ini menunjukkan internal factors lebih berpengaruh dalam strategi pemasaran bisnis pariwisata dibandingkan external factors. Strategi pemasaran bisnis pariwisata dengan produk dan jasa serta harga bisnis pariwisata Kota Davao yang kompetitif sangat menarik, kemampuan sumber daya yang handal dalam berbahasa Inggris dan kompetensi teknologi informasi yang baik sebagai modal dasar pariwisata Kota Davao. Diversifikasi produk dan jasa bisnis pariwsata (dive tourism, eco tourism, medical tourism and golf tourism) meningkatkan kunjungan turis domestik dan asing berkunjung ke Kota Davao. Tourism multiplier effects memiliki dampak positif pada berbagai sektor usaha di Kota Davao. Dampak positif peningkatan beberapa indikator antara lain: occupancy rate atau tingkat hunian hotel berbintang dan kelas melati di Kota Davao Sebesar $75 \%$, tenaga kerja yang bekerja tahun 2018 sejumlah 2.862 .500 atau $94,2 \%$ dan tenaga kerja yang tidak bekerja sejumlah 2.906.250 atau 5,8\%, pemilik bisnis pariwisata mengalami peningkatan dari 40.499 tahun 2017 menjadi 41.292 tahun 2019 dan investasi bisnis pariwisata mencapai Rp 74.700.000.000.000.
\end{abstract}

Kata kunci: Strategi Pemasaran, Bisnis Pariwisata, Analisis SWOT, Balik Bayan, Turis Dometik dan Asing

\section{MARKETING STRATEGIES FOR THE TOURISM BUSINESS IN DAVAO CITY, PHILIPPINES}

\section{ABSTRACT}

This study aims to determine the external and internal factors of the tourism business marketing strategy in Davao City, Philippines. This research method is 
qualitative method. The population in this study were all members of travel and tour in Davao City, Philippines by using purposive sampling obtained a sample of 10o. Primary data consisted of interviews with questionnaires, field observations and documentation. Secondary data were obtained from Davao City Tourism Office, Department of Tourism in Region XI, National Economic and Development Authority (NEDA) Region XI, Bureau of Immigration in Region XI, Davao City Travel and Tours. Data analysis using Strengths, Weaknesses, Opportunities and Threats (SWOT) Analysis, Internal Factors Analysis Summary (IFAS) and External Factor Analysis Summary (EFAS) prove that the marketing strategy of the tourism business in Davao City, Philippines, is in the position of the First Quadrant located between external opportunities and internal forces where the results of the analysis obtained a total score of IFAS is 3.36 and EFAS is 3.01 and is at point $X 3.36$ and point $Y 1.57$. This shows that internal factors are more influential in the marketing strategy of the tourism business compared to external factors. The tourism business marketing strategy with products and services as well as the competitive prices of Davao City tourism business, the ability of reliable resources in English and good information technology competence as the basic capital of Davao City tourism. Diversification of tourism products and business services (dive tourism, eco tourism, medical tourism and golf tourism) increases domestic and foreign tourist visits to Davao City. Tourism multiplier effects have a positive impact on various business sectors in Davao City. The positive effects of the increase in several indicators include: occupancy rate or occupancy rate of star hotels and jasmine classes in Davao City by 75\%, labor force working in 2018 was 2,862,500 or $94.2 \%$ and labor force not working was 2,906,250 or 5.8\%, tourism business owners experienced an increase from 40,499 in 2017 to 41,292 in 2019 and tourism business investment reached $R p$ 74,700,000,000,000.

Keywords: Marketing Strategy, Tourism Business, SWOT Analysis, Reverse Bayan, Domestic and Foreign Tourists

Diterima: 15 Agust 2019; Direvisi: 16 Sept 2019; Diterbitkan: 30 Okt 2019

\section{PENDAHULUAN}

Kota Davao sebagai pintu gerbang samudra pacific berbatasan dengan Pulau Miangas Kabupaten Kepulauan Talaud Provinsi Sulawesi Utara. Kota Davao di Pulau Mindanao merupakan kota nomor tiga di Filipina setelah Manila Metropolitan di Pulau Luzon dan Kota Cebu di Pulau Visaya. Davao City merupakan kota terbesar di Filipina ditinjau dari luas wilayahnya mencapai $2.443,61 \mathrm{~km}$ dengan penduduk berjumlah 1.796.574 jiwa tahun 2019.

Kota Davao dikenal sebagai tempat tinggal hewan langka burung elang di Mount Apo yang tidak diketemukan di tempat lainnya di Filipina. Mount Apo adalah (gunung tertinggi di Filipina) dengan ketinggian mencapai 2.954 meter diatas permukaan laut. Kota Davao dengan tanahnya yang subur dikelilingi pegunungan dan laut juga dikenal sebagai keranjang buah-buahan (Durian, Pisang, Nanas, Jeruk, Mangga dan Manggis) Filipina atau Fruit Basket of the Philippines.

Strategi pemasaran dengan brand bisnis pariwisata "MICE (Meeting, Incentives, Convention and Events), back to the nature, Sport Tourism, Balik Bayan and Retiree Visa" sebagai pengggerak pertumbuhan ekonomi dan pembangunan bahkan menjadi bidang usaha unggulan Kota Davao seperti Philippine Eagle Center, Crocodile Park, Eden Nature Park, Mount Apo (The Highest Mountain in the 
Philippine). Malagos and Puentespina Orchid Garden, Durian Park, Apo Golf and Country Club, Rancho Palos Verdes Golf and Country Club.

Belum banyak rute penerbangan regular flight maupun charter flight dari luar negeri menuju Davao International Airport sehingga belum mencapai target market yang diharapkan dikarenakan belum maksimalnya incoming and outgoing passenger and load factors sejak 1995 sampai dengan 2017. 5 penerbangan internasional dari luar negeri ke Davao International Airport terdiri dari: Singapura via Silk Air, Hongkong via Cathay Dragon, Quanzhou, China via Xiamen Air, Qatar via Qatar Airways and Manado via Garuda Indonesia. Perusahaan penerbangan asing ini membawa turis asing berasal dari Amerika Serikat, Korea Selatan, China, Jepang, Inggris, Australia, India, Canada, Singapura, Malaysia, Qatar, Taiwan dan Balik Bayan.

Belum pernah kapal pesiar atau cruise ship dari luar negeri yang membawa penumpang turis asing berkunjung ke Sasa Wharf International Seaport disebabkan karena adanya travel advisory yang dikeluarkan oleh beberapa kedutaan besar asing (Amerika Serikat, Inggris, Australia, Canada) di Manila, Filipina. Beberapa turis asing masih ada saja tetap berkunjung ke Kota Davao meskipun ada travel advisory.

Sebaliknya banyak rute penerbangan dari beberapa bandara dalam negeri di Filipina menuju Davao International Airport seperti Philippines Airlines, Philippines Air Asia, PAL Express and Cebu Pacific. Turis domestik berkunjung ke Kota Davao lebih banyak dilakukan pada bulan Desember dan April sampai dengan Mei karena masa liburan sekolah atau dikenal dengan istilah peak season.

ASEAN Economic Community telah diberlakukan sejak tahun 2017. Namun faktanya belum samanya peraturan keimigrasian di negera-negraa anggota ASEAN tentang turis asing. Bebas visa untuk sesame negara-negara anggota ASEAN diberlakukan selama 30 hari, kecuali Filipina yang memberlakukan bebas visa selama 21 hari. Overstay bagi semua WNA dikenakan denda Php 3.130 per bulan. Sedangkan overstay bagi WNA di Indonesia dikenakan denda Rp 150.000 per hari.

Pemasaran produk dan jasa bisnis pariwisata Kota Davao belum maksimal tersosialisasi kepada Philippine Embassy di luar negeri dan WNP Balik Bayan yang tinggal dan bekerja di luar negeri. Sumber daya alam yang sangat terbatas di Filipina apabila dibandingkan dengan sumber daya alam Indonesis yang luas dan melimpah menyebabkan WNP lebih menyukai bekerja di luar negeri dengan penghasilan lebih besar atau dikenal dengan istilah Overseas Filipino Workers (OFW). Selain itu, Budaya di Filipina banyak WNP menikah dengan WNA kemudian menetap di luar negeri dan juga banyak WNP menikah dengan WNA kemudian tinggal di Filipina atau dikenal dengan istilah special resident retiree's visa.

Kemampuan business communication dalam bahasa Inggris yang baik dengan ratarata tingkat pendidikan WNP minimal sarjana sebagai modal dasar untuk lebih banyak menarik turis domestic dan asing berkunjung ke Kota Davao. Namun demikian masih kurang banyaknya pemandu wisata yang memiliki kemampuan business communication dalam Bahasa Mandirin, Hokkian, Hakka, Korea dan Nihongo menjadi kendala dalam berkomunikasi dengan turis yang berasal dari China, Jepang, Korea Selatan dan Taiwan.

Para pelaku bisnis pariwisata dalam negeri dan luar negeri belum terintegrasi dengan baik dalam manajemen perencanaan digital marketing on tourism business sehingga belum pernah melebih capaian target kunjungan turis domestik dan asing di Kota Davao, Filipina yang telah ditetapkan oleh pemerintah sejak tahun 2016, 2017 dan 2018.

Rata-rata pertumbuhan ekonomi Kota Davao tahun 2016 - 2018 sebesar 9,67 ditunjang dari multiplier effects persediaan sektor pertanian, perikanan, industry dan Micro, Small and Medium Entreprises (MSME) 
untuk memenuhi kebutuhan belanja turis domestik dan asing.

Penelitian ini bertujuan untuk mengetahui strategi pemasaran bisnis pariwisata dan faktor-faktor eksternal serta internal apa sajakah yang mempengaruhi kunjungan turis domestik dan asing di Kota Davao, Filipina

\section{LANDASAN TEORI}

\section{Strategi Pemasaran Bisnis Pariwisata}

Menurut Arens and Wigold, (2013)
dalam bukunya berjudul Contemporary
Advertising, pemasaran adalah proses
merencanakan dan melaksanakan konsep
tentang harga, promosi dan distribusi ide,
barang dan jasa untuk menciptakan pertukaran
yang memuaskan kebutuhan, keinginan dan
tujuan individu atau organisasi.

Menurut Kotler dan Amstrong, (2014) dalam bukunya berjudul principles of marketing mengatakan bahwa marketing mix (bauran pemasaran) adalah susunan tactical marketing tools yang terdiri dari 4P, yaitu Products, Prices, Promotion and Places. Philip Kotler dalam bukunya yang berjudul marketing strategic juga mengatakan bahwa bauran pemasaran adalah kombinasi 4P (Products, Prices, Promotion and Places).

Menurut Avraham \& McMillan, (2016:178), area fungsional yang sangat penting dalam organisasi bisnis pariwisata selalu menggunakan berbagai strategi dan teknik komunikasi untuk mempromosikan daerah dan tujuan. Menurut Donohoe, (2012:130), tujuan pemasaran pariwisata adalah untuk menjual situs ke basis pelanggan potensial dan pemasar Pariwisata sendiri memastikan bahwa mereka memenuhi dua kriteria yang dibutuhkan pelanggan dan tujuan organisasi tercapai.

Menurut Lei, Kostopoulou dan Huibin, (2014:17), kualitas tujuan wisata adalah kunci keberhasilan dalam pengembangan pariwisata dan peran pemasaran dan manajemen pariwisata dalam meningkatkan kualitas tujuan wisata penting untuk diidentifikasi oleh peneliti akademik. Menurut Hartwel, (2016:57), tujuan wisata dianggap sebagai "entitas geografis yang terdefinisi dengan baik dengan nama merek, pencampuran semua produk pariwisata, layanan, dan lingkungan sebagai pengalaman terintegrasi yang dapat dipahami dan diidentifikasi oleh konsumen".

Menurut Tse \& Qiu, (2016:15-170 dan Simon et al., (2014), penting bagi pemasar pariwisata tidak hanya untuk mempromosikan jumlah kedatangan wisatawan yang lebih besar tetapi juga kualitas pengalaman wisata, termasuk daya dukung sosial dan lingkungan untuk pengembangan tujuan yang berkelanjutan

Gössling et al., (2016: 528) menyatakan bahwa "daya tarik destinasi mempengaruhi waktu kunjungan wisatawan dari tingkat permintaan, kemauan untuk membayar dan keinginan untuk tinggal" Polo-Pena, Jamilena dan Molina (2012: 517-520) mencatat bahwa keberlanjutan tujuan menarik politisi dan komunitas bisnis dan juga kemudian digunakan sebagai alat pemasaran untuk pemasaran tujuan.

Donohoe (2012: 128) menunjukkan bahwa Organisasi dan manajemen Pemasaran Pariwisata memiliki peran vital untuk bermain dengan dukungan dan keterlibatan para pemangku kepentingan, mitra dan masyarakat setempat tentang praktik paradigma pariwisata tujuan berkelanjutan.

\section{Multiplier Effect of Tourism}

Menurut Glenn Kreag, (2001) bahwa pariwisata memiliki kontribusi yang besar terhadap pariwisata yang menghasilkan lapangan pekerjaan baru dan mendapatkan pendapatan dari bisnis pariwisata baru.

Menurut Fermaran, J.A., Legaspi, L and Madero, L., (2013) bahwa pengaruh pariwisata terhadap ekonomi daerah adalah:

1. Pekerjaan dalam sektor jasa;

2. Bisnis jasa transportasi; 
3. Bisnis jasa perhotelan;

4. Bisnis jasa hiburan

Madhuri Sawant, (2010) mengatakan bahwa kegiatan pariwisata mempengaruhi pasar di bidang ekonomi, sosial, lingkungan, pemerintah daerah dan stakeholders lainnya.

Ni Made Ary Widiastini, Nyoman Dini Andiani dan Trianasari, (2012) mengatakan bahwa mengkemas paket wisata dalam berbagai harga dan varian, melakukan diversifikasi produk wisata dan meningkatkan peran serta pemerintah daerah, meningkatkan media promosi melalui penggunaan teknologi informasi, mengembangkan produk yang ramah lingkungan melakukan kreatifitas terhadap produk hotel. Faktor terpenting dalam pemasaran pariwisata adalag peningkatan peran serta pemerintah daerah, melakukan diversifikasi produk dan meningkatkan kualitas layanan pariwisata.

Rusu, (2011) mengatakan bahwa pariwisata tidak hanya menciptakan pekerjaan pada tertiary sector, tetapi juga mendukung petumbuhan primary and secondary sectors atau dikenal dengan istilah multiplier effect of tourism. Efek berganda ini membuka bisnis baru dan peluang usaha dalam kehidupan masyarakat. Pariwisata adalah sektor industry beraneka ragam dengan memiliki banyak hubungan dan memerlukan kebutuhan supply chain pada sector lainnya di bidang ekonomi yang kemudian tentunya dapat menguntungkan masyarakat.

Efek berganda terjadi dalam berbagai cara dalam ekonomi yang bergantung pada pariwisata. Cara yang umum adalah pengganda langsung, tidak langsung dan diinduksi. Sebagai contoh, uang yang dibayarkan / dihabiskan di sebuah hotel tidak hanya membantu menciptakan pekerjaan langsung di hotel, tetapi juga menciptakan pekerjaan secara tidak langsung di tempat lain dalam perekonomian (Anderson, 2013).

Hotel harus membeli makanan dari petani setempat yang kemudian dapat menghabiskan sebagian uang ini untuk pupuk atau pakaian sementara permintaan untuk produk lokal meningkat karena turis sering membeli suvenir (Rusu, 2011). Ini berarti bahwa penjualan satu perusahaan memerlukan pembelian dari perusahaan lain dalam perekonomian (Muhanna, 2007).

UNACTAD (2017) berpendapat bahwa hubungan antara pariwisata dan sektor produktif lainnya dan segmen pasar memiliki potensi untuk memacu kewirausahaan lokal melalui peluang bisnis baru. Efek berganda diwujudkan dalam dua bentuk dalam pariwisata seperti dicatat Rusu, (2011). Pertama, efek berganda dari penghasilan dari pariwisata. Kedua, dalam hal efek pengeluaran moneter pariwisata, menciptakan pendapatan baru dalam ekonomi dan pengganda investasi asing.

Grekin dan Milne (1996) mengemukakan kekhawatiran tentang perlunya peningkatan hubungan antar sektor di Indonesiaekonomi dan penambahan tambahan input lokal ke dalam manajemen pariwisata ke dan di masyarakat jika manfaat ingin dimaksimalkan. Perusahaan pariwisata di negara berkembang terdiri dari sebagian besar bisnis di segmen pasar utama seperti akomodasi, transportasi, dan operasi tur. Semakin besar integrasi ekonomi nasional dan keterkaitan berbagai sektornya, semakin banyak manfaat yang diperoleh dari pariwisata (UNWTO, 2002C; Muhanna, 2007). Keterkaitan juga dapat menghasilkan efek berganda di sektor ekonomi lain selain dari pariwisata di masyarakat di mana pariwisata dan kegiatan terkaitnya dilakukan.

Brida dan Pulina (2016) mengakui bahwa beberapa sektor seperti kontribusi sektor perhotelan terhadap ekonomi lokal tidak homogen. Sementara mengutip Andriotis (2002) secara eksplisit mereka mencatat bahwa perusahaan skala besar dapat meningkatkan pendapatan sektor publik melalui tingkat perpajakan yang lebih tinggi tetapi dengan sedikit peluang untuk berdagang dengan pemasok lokal. Oleh karena itu, untuk meningkatkan efek pengganda lokal, kegiatan pariwisata perlu mengaktifkan partisipasi yang lebih tinggi dari investor lokal, menciptakan 
lebih banyak kesempatan kerja bagi penduduk lokal dan hubungan ekonomi insentif dengan pengecer dan grosir lokal (Andriotis, 2002).

Brida dan Pulina (2016) menggunakan analisis multivariat dari berbagai indikator ekonomi seperti pengeluaran rumah tangga, harga dan suku bunga minimum sebagaimana diusulkan oleh Jackman dan Lorde (2010). Indikator ekonomi lain yang digunakan adalah impor barang-barang industri dan mesin, investasi langsung asing ke dalam, transportasi dan komunikasi, hotel dan restoran, iklan dan promosi pengeluaran impor dan ekspor (Louca, 2006; Nowark, et al., 2007; Brida dan Pulina, 2016 ).

\section{Kerangka Pemikiran}

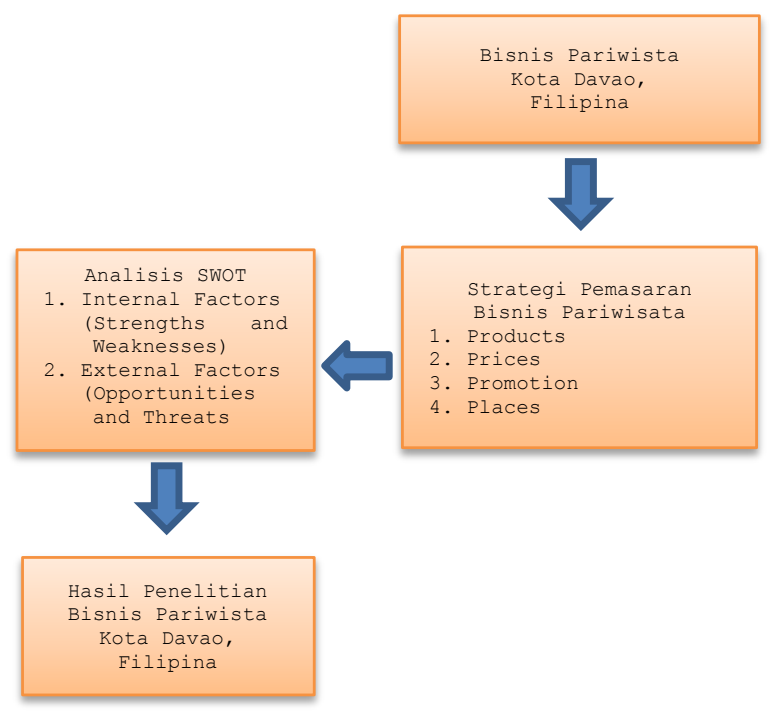

Gambar 1. Kerangka Pemikiran

\section{METODE PENELITIAN}

Metode penelitian yang digunakan adalah qualitative method dengan data dianalisa menggunakan Strengths, Weaknesses, Opportunities and Threats (SWOT) Analysis, External Factor Analysis Summary (EFAS) and Internal Factors Analysis Summary (IFAS). Populasi adalah seluruh anggota Davao City Travel and Tours Association, Philippine dan diperoleh sampel sebanyak 50 orang dilakukan dengan cara purposive sampling. Data primer diperoleh melalui kegiatan wawancara dengan kuesioner berdasarkan dimensi dan indikator serta observasi lapangan dan dokumentasi. Informasi dan data sekunder bersumber dari Davao City Tourism Office, Department of Tourism in Region XI, National Economic and Development Authority (NEDA) Region XI, Bureau of Immigration, Davao City Travel and Tours Association.

\section{HASIL DAN PEMBAHASAN}

\section{Data Sample}

Sample berjumlah 100 orang terdiri dari jenis kelamin laki-laki 34 orang dan wanita 66 orang, hal ini menunjukkan bahwa wanita yang bekerja di Davao City Travel and Tours Association lebih banyak dibandingkan dengan laki-laki. Umur responden berusia 19-28 tahun berjumlah 54 orang, $29-38$ tahun berjumlah 29 orang, $39-48$ tahun berjumlah 20 orang dan $49-58$ tahun berjumlah 7 orang.

Tingkat pendidikan responden terdiri dari 69 orang bergelar Sarjana S1, 28 orang bergelar magister S2 dan 3 orang bergelar doktor S3. Tidak ada pegawai Davao City Travel and Tours Association yang berpendidikan SD sampai dengan SMA karena biaya pendidikan gratis atau sangat rendah apabila sekolah negeri sampai dengan perguruan tinggi negari mendapat subsidi dari pemerintah Filipina. Selain itu, sudah menjadi budaya orang tua yang selalu menginginkan anak-anaknya melanjutkan kuliah minimal Diploma atau Sarjana.

\section{Wisatawan Domestik dan Asing}

Tabel 1. Turis Domestik berkunjung ke Kota Davao Tahun $2014-2018$

\begin{tabular}{|l|l|l|}
\hline Tahun & $\begin{array}{l}\text { Wisatawan } \\
\text { Domestik }\end{array}$ & Persentase \\
\hline 2014 & 1.529 .907 & \\
\hline 2015 & 1.730 .009 & $11,57 \%$ \\
\hline 2016 & 1.716 .224 & $-0,80 \%$ \\
\hline
\end{tabular}




\begin{tabular}{|l|l|l|}
\hline 2017 & 2.009 .879 & $14,61 \%$ \\
\hline 2018 & 2.390 .000 & $15,90 \%$ \\
\hline 2019 & 3.000 .000 (target) & \\
\hline & Rata-Rata & $10,32 \%$ \\
\hline
\end{tabular}

Sumber: Davao City Tourism Office, 2019

Rata-rata kunjungan turis domesik ke Kota Davao tahun 2014 - 2018 sebesar 10,32\%. Rata-rata kunjungan turis asing ke Kota Davao tahun 2016 - 2018 sebesar 49,21\%. Rata-rata kunjungan turis domesik dan asing ke Kota Davao tahun 2014 - 2018 sebesar 29,77\%.

Tabel 2. Turis Asing Berkunjung ke Kota Davao

\begin{tabular}{|l|l|l|}
\hline Tahun & $\begin{array}{l}\text { Wisatawan } \\
\text { Asing }\end{array}$ & Persentase \\
\hline 2016 & 23.256 & $68,86 \%$ \\
\hline 2017 & 74.684 & $29,55 \%$ \\
\hline 2018 & 106.015 & $\begin{array}{l}150.000 \\
\text { (target) }\end{array}$ \\
\hline 2019 & Rata-Rata & $49,21 \%$ \\
\hline
\end{tabular}

Sumber: Davao City Tourism Office, 2019

Tabel 3. Negara Asal Turis Asing Yang Berkunjung ke Kota Davao

\begin{tabular}{|l|l|l|}
\hline Negara Asal & 2018 & 2017 \\
\hline Amerika Serikat & 21.324 & 20.779 \\
\hline Jepang & 12.800 & 12.510 \\
\hline China & 10.827 & 9.231 \\
\hline Korea & 8.936 & 7.550 \\
\hline Australia & 7.117 & 5.929 \\
\hline India & 6.509 & 4.976 \\
\hline Canada & 5.392 & 4.016 \\
\hline
\end{tabular}

\begin{tabular}{|l|l|l|}
\hline Singapura & 4.985 & 4.040 \\
\hline Inggris & 4.287 & 3.282 \\
\hline Malaysia & 2.449 & \\
\hline Qatar & 2.703 & 2.371 \\
\hline Taiwan & 1.868 & \\
\hline Jumlah & 106.015 & 74.684 \\
\hline
\end{tabular}

Sumber: Davao City Tourism Office, 2019

Turis asing asal Amerika Serikat menempati urutan pertama. Urutan kedua adalah Jepang karena faktor sejarah kolonialisme dimana keturunan WNP yang menikah dengan WN Jepang membentuk suau organisasi yang dikenal dengan nama Philippine Nikei Jin Kai.

Tabel 4. Balik Bayan (WNP Yang Bekerja dan Tinggal di Luar Negeri

\begin{tabular}{|l|l|l|l|}
\hline Nama & 2017 & 2016 & $\begin{array}{l}\text { Persen } \\
\text { tase }\end{array}$ \\
\hline Balik Bayan & 47.872 & 23.256 & 35,56 \\
\hline
\end{tabular}

Balik bayan adalah WNP yang bekerja di luar negeri atau WNP yang menikah dengan WNA dan tinggal di luar negeri. Balik bayan ini memiliki dual citizenship (1 WNP dan 1 WNA) atau kewarganegaraan ganda. Sudah merupakan budaya Filipina bahwa lulusan PTN dan PTS lebih banyak bekerja di luar negeri dengan penghasilan lebih besar dari pada di dalam negeri. Budaya di Filipina juga ada kebanggaan bagi orang tua apabila anaknya dapat menikah dengan WNA.

Tabel 5. Beberapa Kali Kunjungan Turis ke Kota Davao

\begin{tabular}{|l|l|l|}
\hline $\begin{array}{l}\text { 1 Kali } \\
\text { Kunjungan }\end{array}$ & $\begin{array}{l}\text { Lebih dari 1 } \\
\text { kali } \\
\text { kunjungan }\end{array}$ & Keterangan \\
\hline $\begin{array}{l}\text { 258\% atau } \\
\text { 25 turis }\end{array}$ & $\begin{array}{l}75 \% \text { atau 75 } \\
\text { turis }\end{array}$ & $\begin{array}{l}\text { Beberapa kali } \\
\text { kunjungan turis ke } \\
\text { Kota Davao lebih } \\
\text { banyak } \\
\text { dibandingakan 1 } \\
\text { kali kunjungan }\end{array}$ \\
\hline
\end{tabular}

Sumber: Diolah oleh Peneliti, 2018 
Tabel 6. Turis Berkunjung Sendiri, keluarga, Teman dan Organisasi ke Kota Davao

\begin{tabular}{|l|l|l|l|}
\hline Sendiri & Keluarga & Teman & Organisasi \\
\hline $12 \%$ & $38 \%$ & $21 \%$ & $28 \%$ \\
\hline
\end{tabular}

Sumber: Diolah oleh Peneliti, 2018

Tabel 7. Sumber Informasi Turis ke Kota Davao

\begin{tabular}{|l|l|l|l|}
\hline Teman & Televisi & Internet & $\begin{array}{l}\text { Magazine and } \\
\text { Newspaper }\end{array}$ \\
\hline $15 \%$ & $6 \%$ & $68 \%$ & $9 \%$ \\
\hline
\end{tabular}

Sumber: Diolah oleh Peneliti, 2018

Tabel 8. Transportasi Lokal Turis di Kota Davao

\begin{tabular}{|c|c|c|}
\hline Taxi & Jeepney & Sewa Mobil \\
\hline $45 \%$ & $16 \%$ & $39 \%$ \\
\hline
\end{tabular}

Sumber: Diolah oleh Peneliti, 2018

Tabel 9. Akomodasi Turis di Kota Davao

\begin{tabular}{|c|c|c|}
\hline Hotel & $\begin{array}{c}\text { Rumah } \\
\text { Teman }\end{array}$ & $\begin{array}{c}\text { Second } \\
\text { Home }\end{array}$ \\
\hline $66 \%$ & $14 \%$ & $20 \%$ \\
\hline
\end{tabular}

Sumber: Diolah oleh Peneliti, 2018

Lebih dari 1 kali kunjungan turis domestik dan asing ke Kota Davao sebanyak 75\% dan turis bersama keluarga berkunjung ke Kota Davao sebanyak $38 \%$ dan informasi tentang bisnis pariwisata Kota Davao bersumber dari internet sebanyak 68\%. Turis menggunakan jasa transportasi lokal dengan taxi $45 \%$, sewa mobil $39 \%$ dan angkutan umum jeepney $16 \%$. Turis domestik dan asing ke Kota Davao lebih suka tinggal di hotel 66\% dibandingkan rumah teman atau second home (rumah milik turis namun sudah ditempati keluarga turis)

Tabel 10. Kamar Hotel di Sulwesi Utara tahun 2018

\begin{tabular}{|l|l|l|}
\hline $\begin{array}{l}\text { Hotel Kelas } \\
\text { Bintang }\end{array}$ & $\begin{array}{l}\text { Hotel Kelas } \\
\text { Melati }\end{array}$ & Keterangan \\
\hline 45 hotel & 203 Hotel & $\begin{array}{l}\text { 2.618 kamar hotel } \\
\text { kelas bintang dan }\end{array}$ \\
\hline
\end{tabular}

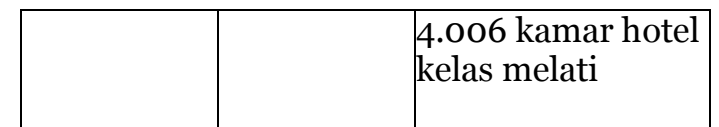

Sumber: Davao City Tourism Office, 2018

Tabel 11. Alasan Turis Berkunjung ke Kota Davao tahun 2018

\begin{tabular}{|l|l|l|l|}
\hline $\begin{array}{l}\text { Rekreasi } \\
\text { atau } \\
\text { Liburan }\end{array}$ & $\begin{array}{l}\text { Bisnis atau } \\
\text { Kerja }\end{array}$ & $\begin{array}{l}\text { Kunjungan } \\
\text { Teman }\end{array}$ & $\begin{array}{l}\text { Festival } \\
\text { Budaya }\end{array}$ \\
\hline 41 & 16 & 14 & 29 \\
\hline
\end{tabular}

Sumber: Diolah oleh Peneliti, 2018

Alasan turis domestik dan asing berkunjung ke Kota Davao lebih banyak rekreasi atau liburan dan fetsival budaya. Kunjungan turis asing ini didukung oleh keberadaan Davao International Airport yang memiliki 5 rute penerbangan asing (Silk Air, Cathay Dragon, Xiamen Air, Qatar Airways dan Garuda Indonesia) menuju negara Singapura, Hongkong, Quanzhou, Qatar dan Indonesia.

Tabel 12. International Direct Flight to Davao International Airport Tahun 2018 - 2019

\begin{tabular}{|l|l|l|}
\hline Airline & $\begin{array}{l}\text { City and } \\
\text { Country }\end{array}$ & Frequency \\
\hline Silk Air & Singapore & 5 times per week \\
\hline $\begin{array}{l}\text { Cathay } \\
\text { Dragon }\end{array}$ & Hongkong & 4 time per week \\
\hline Xiamen Air & $\begin{array}{l}\text { Quanzhou, } \\
\text { China }\end{array}$ & 2 times per week \\
\hline $\begin{array}{l}\text { Qatar } \\
\text { Airways }\end{array}$ & Doha, Qatar & Once per week \\
\hline $\begin{array}{l}\text { Garuda } \\
\text { Indonesia }\end{array}$ & $\begin{array}{l}\text { Manado, } \\
\text { Indonesia }\end{array}$ & 2 times per week \\
\hline Sumber: Bureau of Immigration, 2019
\end{tabular}

Tabel 13. Tujuan Wisata Turis Domestik dan Asing ke Kota Davao

\begin{tabular}{|c|c|}
\hline Tujuan Wisata & Jumlah \\
\hline Samal Island Resort & 33 \\
\hline $\begin{array}{c}\text { Philippine Eagle Nature } \\
\text { Center }\end{array}$ & 19 \\
\hline Malagos Garden Resort & 15 \\
\hline Crocodile Park & 15 \\
\hline Eden Nature Park & 13 \\
\hline Gap Farming & 5 \\
\hline Jumlah & 100 \\
\hline
\end{tabular}

Sumber: Diolah oleh Peneliti, 2019 
Tabel 14. Indikator Pariwisata Sulawesi Utara Tahun 2018

\begin{tabular}{|c|c|c|}
\hline $\begin{array}{l}\text { Lamanya } \\
\text { Tinggal }\end{array}$ & 11 hari & $\begin{array}{l}\text { Pendapatan untuk } \\
\text { hotel, restoran dan } \\
\text { tempat rekreasi }\end{array}$ \\
\hline $\begin{array}{l}\text { Tingkat } \\
\text { Hunian Hotel }\end{array}$ & $70 \%-80 \%$ & \\
\hline $\begin{array}{l}\text { Belanja Turis } \\
\text { Asing }\end{array}$ & $\begin{array}{l}\text { Rp 5 juta per } \\
\text { hari }\end{array}$ & $\begin{array}{l}5 \text { juta } \times 106.015 \text { turis } \\
\text { asing }= \\
530.075 .000 .000\end{array}$ \\
\hline $\begin{array}{l}\text { Belanja Turis } \\
\text { Domestik }\end{array}$ & $\begin{array}{l}\text { Rp 2,5 juta } \\
\text { per hari }\end{array}$ & $\begin{array}{l}2,5 \text { juta } \times 2.390 .000 \\
\text { turis domestik }= \\
5.975 .000 .000 .000\end{array}$ \\
\hline
\end{tabular}

Sumber: Dioleh oleh Peneliti, 2019

Tabel 15. Tourism Multiple Effects di Sulawesi Utara Tahun 2018

\begin{tabular}{|c|c|c|}
\hline $\begin{array}{l}\text { Bidang } \\
\text { Usaha }\end{array}$ & Indikator & Keterangan \\
\hline Tenaga Kerja & $\begin{array}{l}\text { Tenaga kerja } \\
\text { yang bekerja } \\
94,2 \% \text { tahun } \\
\text { 2015 dengan } \\
\text { tingkat } \\
\text { pengangguran } \\
5,8 \%\end{array}$ & $\begin{array}{l}\text { Tenaga kerja } \\
\text { berjumlah } \\
\text { 2.862.500 tahun } \\
\text { 2014 dan } \\
\text { 2.906.250 tahun } \\
2015\end{array}$ \\
\hline $\begin{array}{l}\text { Pemilik Bisni } \\
\text { Pariwisata }\end{array}$ & $\begin{array}{l}40.499 \text { tahun } \\
2017 \text { menjadi } \\
41.292 \text { tahun } \\
2017\end{array}$ & $\begin{array}{l}\text { Terdapat } \\
\text { peningkatan } \\
\text { jumlah bisnis } \\
\text { pariwisara }\end{array}$ \\
\hline Investasi & $\begin{array}{l}\text { Investasi bisn } \\
\text { pariwisata } \\
\text { mencapai } \\
74.700 .000 . \\
000.000\end{array}$ & $\begin{array}{l}\text { s Penambahan } \\
\text { kamar hotel } \\
\text { sebanyak } 1.000 \\
-2.000\end{array}$ \\
\hline
\end{tabular}

Sumber: National Economic and Development Authority, 2018

Tabel 16. Pertumbuhan Ekonomi Kota Davao

\begin{tabular}{|l|l|}
\hline Tahun & Pertumbuhan Ekonomi \\
\hline 2016 & $9,5 \%$ \\
\hline 2017 & $10,9 \%$ \\
\hline 2018 & $8,6 \%$ \\
\hline 2019 & 9,0 (target) \\
\hline Rata-Rata & $9,67 \%$ \\
\hline
\end{tabular}

Sumber: Diolah oleh Peneliti, 2019

\section{Matriks EFAS / IFAS}

Berdasarkan hasil penelitian bahwa Internal Factors diperoleh dari products, prices, places and promotion serta External Factors diperoleh dari strategi pariwisata pemerintah Kota Davao, keindahan alam wisata alam, pelayanan, transportasi dan keamanan. Untuk menentukan bobot o,o sampai dengan 1,0 berdasarkan nilai rata-rata kuesioner dan untuk menentukan rating 1 sampai dengan 4 penilaian dari anggota Davao City Tours and Travel Agencies.

Table 17. Internal Factors Analysis Summary (IFAS)

\begin{tabular}{|c|c|c|c|c|}
\hline No. & Faktor Internal & Bobot & Rating & Nilai \\
\hline \multicolumn{5}{|c|}{ Strenghts } \\
\hline 1 & $\begin{array}{l}\text { Turis domestik dan } \\
\text { asing berkunjung } \\
\text { ke Kota Davao } \\
\text { tertarik dengan } \\
\text { produk dan jasa } \\
\text { bisnis pariwisata }\end{array}$ & 0,16 & 4 & 0,64 \\
\hline 2 & $\begin{array}{lr}\text { Harga akomodasi } \\
\text { dan transportasi } \\
\text { bagi turis domestik } \\
\text { dan r asing } \\
\text { terjangkau }\end{array}$ & 0,10 & 3 & 0,30 \\
\hline 3 & $\begin{array}{l}\text { Turis domestik dan } \\
\text { asing mendapatkan } \\
\text { informasi bisnis } \\
\text { pariwisata Kota } \\
\text { Davao bersumber } \\
\text { dari internet }\end{array}$ & 0,14 & 4 & 0,64 \\
\hline 4 & $\begin{array}{l}\text { Digital marketing } \\
\text { mempermudah } \\
\text { turis domestik dan } \\
\text { asing berkunjung } \\
\text { ke Kota Davao }\end{array}$ & 0,11 & 3 & 0,33 \\
\hline 5 & $\begin{array}{l}\text { Pemerintah Kota } \\
\text { Davao aktif } \\
\text { memasarkan bisnis } \\
\text { pariwisata di dalam } \\
\text { negeri dan luar } \\
\text { negeri }\end{array}$ & 0,07 & 3 & 0,21 \\
\hline 6 & $\begin{array}{l}\text { Wisata alam, dan } \\
\text { wisata bahari dan } \\
\text { fetsival budaya } \\
\text { menjadi daya tarik } \\
\text { bagi wisatawan } \\
\text { domestik dan asing } \\
\text { berkunjung ke Kota } \\
\text { Davao }\end{array}$ & 0,12 & 4 & 0,64 \\
\hline & Subtotal & 0,70 & & 2,76 \\
\hline \multicolumn{5}{|c|}{ Weaknesses } \\
\hline 1 & $\begin{array}{l}\text { Harga pesawat, } \\
\text { hotel dan tempat }\end{array}$ & 0,11 & 3 & 0,30 \\
\hline
\end{tabular}




\begin{tabular}{|c|c|c|c|c|}
\hline & $\begin{array}{l}\text { wisata di Kota } \\
\text { Davao cukup mahal }\end{array}$ & & & \\
\hline 2 & $\begin{array}{l}\text { Promosi pelaku } \\
\text { bisnis pariwisata } \\
\text { Kota Davao di } \\
\text { dalam negeri dan } \\
\text { luar negeri belum } \\
\text { terintegrasi }\end{array}$ & 0,08 & 2 & 0,14 \\
\hline 3 & $\begin{array}{l}\text { Tour guide dan } \\
\text { petugas keamanan } \\
\text { memiliki } \\
\text { keterbatasan dalam } \\
\text { berkomunikasi } \\
\text { bahasa Mandarin, } \\
\text { Nihongo dan Korea }\end{array}$ & 0,05 & 2 & 0,10 \\
\hline 4 & \begin{tabular}{lr} 
Lokasi & tujuan \\
wisata & belum \\
dilengkapi & fasilitas \\
\multicolumn{2}{l}{ yang memadai }
\end{tabular} & 0,06 & 1 & 0,06 \\
\hline \multicolumn{2}{|c|}{ Subtotal } & 0,30 & & 0,60 \\
\hline \multicolumn{2}{|c|}{ TOTAL } & 1,0 & & 3,36 \\
\hline
\end{tabular}

Sumber: Diproses oleh Peneliti, 2019

Table 18. External Factors Analysis Summary (EFAS) Matriks

\begin{tabular}{|c|c|c|c|c|}
\hline No & Faktor Eksternal & Bobot & Rating & Nilai \\
\hline \multicolumn{5}{|c|}{ Opportunities } \\
\hline 1 & $\begin{array}{l}\text { Kebijakan } \\
\text { pemerintah Kota } \\
\text { Davao dan Filipina } \\
\text { mendukung } \\
\text { pembangunan } \\
\text { sarana dan } \\
\text { prasarana Davao } \\
\text { International } \\
\text { Airport and Sasa } \\
\text { Wharf } \\
\text { International } \\
\text { Airport }\end{array}$ & 0,15 & 4 & 0,60 \\
\hline 2 & $\begin{array}{l}\text { Paradise Island } \\
\text { Beach and Resort, } \\
\text { Philippine Eagle } \\
\text { Center, Eden Nature } \\
\text { Park, Crocodile } \\
\text { Park menjadi daya } \\
\text { tarik wisatawan } \\
\text { domestik dan asing } \\
\text { berkunjung ke Kota } \\
\text { Davao }\end{array}$ & 0,18 & 3 & 0,54 \\
\hline 3 & $\begin{array}{l}\text { Penduduk Kota } \\
\text { Davao sebagai } \\
\text { pelaku dan pemasar } \\
\text { bisnis pariwisata }\end{array}$ & 0,08 & 4 & 0,32 \\
\hline 4 & $\begin{array}{l}\text { Kota Davao aman } \\
\text { dan tertib }\end{array}$ & 0,09 & 3 & 0,27 \\
\hline 5 & $\begin{array}{l}\text { Turis domestik dan } \\
\text { asing serta Balik } \\
\text { Bayan berdampak } \\
\text { postif terhadap } \\
\text { pendapatan } \\
\text { masyarakat }\end{array}$ & 0,14 & 4 & 0,56 \\
\hline & Subtotal & 0,64 & & 2,29 \\
\hline
\end{tabular}

\begin{tabular}{|c|c|c|c|c|}
\hline 1 & $\begin{array}{l}\text { Peringatan } \\
\text { perjalanan atau } \\
\text { travel warning } \\
\text { mempengaruhi } \\
\text { kunjung turis } \\
\text { domestik dan asing } \\
\text { ke Kota Davao }\end{array}$ & 0,11 & 1 & 0,11 \\
\hline 2 & $\begin{array}{l}\text { Tujuan wisata } \\
\text { Boracay dan Cebu } \\
\text { merupakan } \\
\text { pesaingn dalam } \\
\text { bisnis pariwisata } \\
\text { Kota davao }\end{array}$ & 0,06 & 2 & 0,12 \\
\hline 3 & $\begin{array}{lr}\text { Persaingan } & \text { bisnis } \\
\text { pariwisata } & \text { Kota } \\
\text { Davao antar travel } \\
\text { and tour, perhotelan } \\
\text { dan tempat wisata } \\
\text { sangat tinggi }\end{array}$ & 0,12 & 3 & 0,36 \\
\hline 4 & $\begin{array}{l}\text { Kurang banyaknya } \\
\text { rute penerbangan } \\
\text { Davao International } \\
\text { Airport ke luar } \\
\text { negeri }\end{array}$ & 0,06 & 2 & 0,12 \\
\hline 5 & $\begin{array}{lr}\text { Keterbatasan } & \text { dana } \\
\text { pemasaran } & \text { bisnis } \\
\text { pariwisata } & \text { Kota } \\
\text { Davao di luar negeri }\end{array}$ & 0,01 & 1 & 0,01 \\
\hline \multicolumn{2}{|c|}{ Subtotal } & 0,36 & & 0,72 \\
\hline \multicolumn{2}{|c|}{ TOTAL } & 1,0 & & 3,01 \\
\hline
\end{tabular}

Sumber : Diproses oleh Peneliti, 2019

\section{PEMBAHASAN}

Strategi pemasaran bisnis pariwisata Kota Davao adalah sebagai berikut:

1. Eco Tourism Package;

2. Community Based Tourism Development;

3. Tourism Guide Books untuk turis yang datang ke Kota Davao;

4. Dive Travel Exchange untuk pertukaran turis asing dan domestik yang memiliki hobi snorkoling, diving and surfing seperti Paradise Island beach and Resort;

5. Medical Travel Exchange untuk pertukaran turis asing dan domestik yang memiliki keahlian di bidang kedokteran dan keperawatan seperti pelatihan, seminar dan workshop di Davao Doctors Hospital, Southern Philippine Medical Center, San Pedro Hospital;

6. Golf Travel Exchange untuk pertukaran turis asing dan domestik yang memiliki hobi bermain golf seperti pelatihan dan turnamen di Apo Golf and Country Club, and Rancho Parlos Verde Golf and Country Club;

7. Adventure Travel Exhange untuk pertukaran turis asing dan domestik yang memiliki hobi mendaki gunung seperti di Mount Apo and 
Eden Nature Park, Loleng's Mountain Spring Resort

8. International Route Development untuk perluasan Davao International Airport and Sasa Wharf International Seaport;

Berdasarkan hasil analisis diperoleh total skor IFAS, adalah 3,36 dan EFAS 3,01. Hal ini menunjukkan internal factors lebih berpengaruh dalam strategi pemasaran bisnis pariwisata Kota Davao dibandingkan external factors. Strategi pemasaran bisnis pariwisata memiliki strengths yang lebih besar dibandingkan dengan weaknesses, begitu pula opportunities lebih besar dibandingkan threats.

Berdasarkan skor IFAS (X) dan EFAS (Y) diperoleh data X dan Y pada titik koordinat 2,16 dan 1,57. Artinya strategi pemasaran bisnis pariwisata Kota Davao berada pada Kuadran I (Pertama). Hal ini menunjukkan strategi pemasaran bisnis pariwisata Kota Davao selanjutnya memfokuskan pasar segementasi kelas menengah ke atas sehingga diperlukan integrated tourism marketing dan peningkatan kualitas sumber daya manusia, tourism data base, international and domestic networking. Segmentasi menengah $k e$ atas memiliki kekhususan karena kenyamanan, keamanan dan ketertiban, fasilitas yang lengkap, transportasi jalan yang baik.

Berdasarkan hasil penelitian, peneliti mencatat bahwa Tourism multiplier effects di Kota Davao ini memberikan kontribusi pertumbuhan ekonomi tahun 2016 - 2018 sebesar 9,67\%. Belanja turis asing Rp 5 juta per hari dengan 106.015 turis asing tahun 2018 diperoleh pendapatan $\mathrm{Rp}$ 530.000.000.000 dan belanja turis domestik $\mathrm{Rp} 2,5$ juta per hari dengan 2.390.000 turis asing tahun 2018 diperoleh pendapatan Rp 5.975.000.000.000. Hal ini dapat dikatakan bahwa tourism multiplier effects memiliki dampak positif pada berbagai sektor usaha di Kota Davao. Dampak positif peningkatan beberapa indikator antara lain: occupancy rate atau tingkat hunian hotel berbintang dan kelas melati di Kota Davao Sebesar $75 \%$, tenaga kerja yang bekerja tahun 2018 sejumlah 2.862 .500 atau $94,2 \%$ dan tenaga kerja yang tidak bekerja sejumlah
2.906.250 atau $5,8 \%$, pemilik bisnis pariwisata mengalami peningkatan dari 40.499 tahun 2017 menjadi 41.292 tahun 2019, investasi bisnis pariwisata mencapai Rp 74.700.000.000.000.

Berdasarkan uraian tersebut diatas, Marketing startegies for the toruism business di Kota Davao, Filipina menurut peneliti, Soehardi dari Universitas Bhayangkara Jakarta Raya adalah sebagai berikut:

1. Kebijakan pemerintah daerah dan pusat dalam mendukung aksesibilitas transportasi udara, laut dan darat seperti pembangunan infrastruktur International Airport and Seaport;

2. Daya tarik daerah tujuan wisata attractif agar banyak turis domestik dan asing berkunjung ke tempat-tempat pariwisata;

3. Jejaring media sosial dalam mempromosikan produk dan jasa bisnis pariwsata;

4. Pemasaran produk dan jasa pariwisata melalui smartphone agar lebih efektif dan efisien;

5. Membentuk gugus tugas pariwisata terintegrasi atau Integrated Tourism Task Force dalam menyatukan perencanaan, pelaksanaan, pengorganisasian dan monitoring and evaluation;

6. Perlu dukungan Integrated software program yang mengikuti perkembangan new information and communication technology begitu pesat dalam mendukung transaksi pembayaran produk dan jasa bisnis pariwsata;

7. Peningkatan kualitas dan kuantitas sumber daya manusia pelaku dan pegawai bisnis pariwsata yang memiliki kompetensi sertifikasi nasional dan internasional

8. Kemudahan pelasayanan Accessability di tempat Financial technology (Fintech)

Penelitian ini mendukung penelitian sebelumnya yang dilakukan oleh Ni Made Ary Widiastini, Nyoman Dini Andiani dan Trianasari, (2012) dengan judul "Startegi pemasaran Pariwisata di Kabupaten Buleleng, Bali seperti faktor terpenting dalam pemasaran pariwisata adalag peningkatan peran serta pemerintah daerah, melakukan diversifikasi produk dan meningkatkan kualitas layanan pariwisata. 


\section{KESIMPULAN DAN REKOMENDASI}

Kesimpulan dalam penilitian ini adalah sebagai berikut:

1. Skor IFAS, adalah 3,36 dan EFAS 3,01 serta strategi pemasran bisnis pariwisata Kota Davao berada pada titik X 3,36 dan titik Y 1,57. Hal ini menunjukkan internal factors lebih berpengaruh dalam strategi pemasaran bisnis pariwisata dibandingkan external factors. Strategi pemasaran bisnis pariwisata dengan produk dan jasa serta harga bisnis pariwisata Kota Davao yang kompetitif sangat menarik sehingga strengths lebih besar dibandingkan dengan weaknesses. Begitupula opportunities dengan kemampuan sumber daya yang handal dalam berbahasa Inggris dan kompetensi teknologi informasi yang baik sebagai modal dasar pariwisata Kota Davao lebih baik dibandingkan threats dengan produk dan jasa pariwsata Boracay dan Cebu City.

2. Diversifikasi produk dan jasa bisnis pariwsata (dive tourism, eco tourism, medical tourism and golf tourism) meningkatakn kunjungan turis domestik dan asing berkunjung ke Kota Davao.

3. Kebijakan pemerintah mendukung pengembangan Davao International Airport dan Sasa Wharf International Seaport semakin meningkatkan kunjungan turis domestik dan asing ke Kota Davao.

4. Tourism multiplier effects memiliki dampak positif peningktan pertumbuhan ekonomi, penambahan pemilik bisnis pariwisata dan peningktan kesempatan kerja dan peningkatan pendapatan Kota Davao.

Rekomendasi dalam penilitian ini adalah Pemerintah Kota Davao sebaiknya melakukan peningkatan kegiatan sosialisasi Tourism Road Map, Strategic Plan and Road Show kepada stakeholders serta promosi pemasaran bisnis pariwisata di dalam negeri dan luar negeri dengan melibatkan Foreign and Philippine Embassy, Foreign Airlines and Travel and Tours, and also Balik Bayan atau Overseas Filipino Workers. Peningkatan strategi pemasaran bisnis pariwisata diharapkan dapat lebih meningkatkan kunjungan wisatawan domestik dan asing ke Kota Davao. Strategi pemasaran bisnis pariwisata Kota Davao terus menjaga kelestarian alam dan terus melengkapi dan memperluas infrastruktur Davao City Internasional Airport dan sasa Wharf International Seaport.

\section{REFERENSI}

Anderson, W. (2013). Leakages in the Tourism Systems: Case of Zanzibar. Tourism Review, 68 (1), $62 \quad-\quad 76$. http://dx.doi.org/10.1108/16605371311 310084 [Accessed 15 April 2016].

Andriotis, K, (2002). Scale of Hospitality Firms and Local Economics Development Evidence From Crete. Tourism Management. Crete: Greek Islands, Greece.

Arens and Weigold, (2013). Contemporary Advetsising.

Avraham. A., Ketter. E. \& McMillan. P. (2016). Tourism marketing for Developing Countries: Battling Stereotypes and crises in Asia, Africa and the Middle East, Annals of Tourism Research, 60,169-187.

Brida, J. G., Cortes-Jimenez, I., \& Pulina, $M$. (2016). Has the tourism-led growth hypothesis been validated? A literature review. Current Issues in Tourism, 19(5), 394-430. DOI: 10.1080/13683500.2013.868414

[Accessed 15 December 2017].

Donohoe, M. H. (2012). Sustainable heritage tourism marketing and Canadas Rideau canal world heritage site, Journal of Sustainable Tourism, Vol. 2O, No.1, 121-142, Routledge, London.

Generoso Texson, (2019). Davao City Records 1.o3 Million Tourist in First 5 Months of 2019. Davao City: Philippines or https://news.mb.com.ph/2019/o7/o2/d avao-city-records-1-O3-million-touristsin-first-5-months-of-2019/

Gösslling, S., Ring, A., Dwyer, L., Andersson, A. \& Hall, M.C. (2016). Optimizing or Maximizing growth? A challenge for sustainable tourism, Journal of Sustainable Tourism, 24:4, 527-548, Routledge, London. Hall, M. C. (2016). 
Intervening in academic interventions: framing Social Marketing's Potential for Successful Sustainable Tourism behavioural change, Journal of Sustainable Tourism, 24: 3,350-375

Grekin J. \& Milne S. (1996). 'Toward sustainable tourism development: The case of Pond Inlet', in Butler R. W., Hinch T. (eds) 'Indigenous Tourism', Routledge, London, pp. 76-106.

Glenn Kreag, (2001). The Impact of Tourism. New York: University of Minnesota.

Jose Carlitos Licas, (2019). 148,387 Foreign Nationals Residing in the Philippines Report to Immigration Bureau. Manila: Philippines or https://news.abscbn.com/news/o3/24/19/1480ooforeign-nationals-residing-in-phreport-to-immigration-bureau

Lei, W., Kostopulou, S. and Huibin, Y., (2014). The Relation of Destination Marketing and Destination Management from a Theoritical Perspective. International Conference on International Business, ICIB.

Madhuri Sawant, (2010). Socio - Economic Impacts of Tourism Development at Aurangabad District. Aurangabad, Maharashtra: India atau https://www.researchgate.net/publicat ion/315492199_Socio_-

_Economic_impacts_of_Tourism_dev elopment_at_Aurangabad_District

Mahatia Jackman and Troy Lorde, (2010). On the Relationship Between Tourists Flows and Household Expenditure in Barbados: A Dynamic OLS Approach. Economics Bulletin, AccesEcon, Vol. 30(1).

Maria Lourdes Lim, (2018). Davao Region Posts 8.6 Percent Growth in 2018 Highly Commendable. Davao City, Philippine or https://pia.gov.ph/news/articles/102 1453

Muhanna, E. (2007). Tourism Development Strategies and Poverty Elimination. Problems and Perspectives in Management, (5), 37-49.

Ni Made Ary Widiastini, Nyoman Dini Andiani dan Trianasari, (2012). Startegi
Pemasaran Pariwisata di Kabupaten Buleleng, Bali. Buleleng: Bali.

Philip Kotler and Amstrong, (2014). Principles of Marketing

Rusu, S. (2011). Tourism multiplier effect: Journal of Economics and Business Research, XVII, (1), 70-76.

Tanya Rabat Tan, (2019). 2.2 Million tourist visit Davao Region in $1^{\text {st }}$ Half of 2019. Davao City: Philippines or https://www.sunstar.com.ph/article/18 $26,512$.

Tse, T. S. M.and Qiu, H., (2016). Issues Arising from Rapid Growth of Maninland Chinese Visitirs to Hongkong: Implication for Tourism Marketing. Journal of China Tourism Research, 12(3-4), 291-312.

UNWTO, (2011). The Indirect Impact of Tourism: An Economic Analysis. France: thw Third Meeting of Tourism.

Gypsy Mae B. Casurao dan Hazel Princess M. Rebollo. Davao Life is here: Characterizing Inbound Tourists. Davao City: Philippine. http://globalbizresearch.org/Singapor e Conference/pdf/pdf/S485.pdf 